\title{
Evaluation of Prognostic Value of Serum Matrix Metalloproteinases (MMP)-2 and MMP-9 in Canine Mammary Gland Tumors; A Longitudinal Study
}

\section{Zohreh Khaki}

Faculty of Veterinary Medicine, University of Tehran

vahid Fathipour ( $\square$ vahid.vet83@gmail.com)

Faculty of Veterinary Medicine, University of Tehran

\section{Research Article}

Keywords: Canine mammary tumor, MMP-2, MMP-9, Gelatin zymography

Posted Date: March 26th, 2021

DOI: https://doi.org/10.21203/rs.3.rs-271056/v1

License: @ (i) This work is licensed under a Creative Commons Attribution 4.0 International License. Read Full License 


\section{Abstract}

Background: Serum levels of MMP-2 and MMP-9 were evaluated in 26 dogs with mammary tumors before surgical treatment and then 1, 4 and 12 months after surgery by gelatin zymography. Serum samples from 26 dogs with the normal condition were used as the control in the zymographic evaluation. In addition, pathology evaluation was performed in patients.

Results: Our results showed that lymph node metastases are risk factor for death and metastasis and or recurrence $(M / R)$ in canine malignant mammary tumors. Dogs with benign and malignant mammary tumors showed bands of Pro-MMP-2, Pro-MMP-9 and active MMP-9 with molecular weights of 72, 92 and 82, respectively. However, only Pro-MMP-2 and Pro-MMP-9 bands appeared in the serum of control group and two patients with benign lobular hyperplasia tumor. Our results showed that Pro-MMP-2 levels increased more dramatically ( 2 fold) in malignant tumors than in benign tumors and control groups. Also, in patients with $M / R$, there was a significant increase in the levels of Pro-MMP-9 in serum samples 12 months after surgery compared with other sampling times. Meanwhile, the presence of active MMP-9 (especially in samples 4 and 12 months after surgery of malignant tumors), regardless of its amount, is important in terms of prognosis for recurrence or metastasis. Also, active MMP-2 was only detected in some malignant and metastatic tumors. Observation of active MMP- 2 band is very important for M/R than active MMP-9 because its presence regardless of values coincides with a definite M/R, unlike the active form of MMP-9. Necrosis, stromal invasion, and infiltrative growth increase risk of the development of $M / R$ and the presence of necrosis is a risk factor for death.

Conclusions: In conclusion, serum zymograhpy may be used at regular intervals after surgery to check for the possibility of $M / R$ in dogs with mammary tumors. More research is needed in this regard.

\section{Introduction}

Mammary tumors are the most common type of tumor that is reported in intact bitches and about $50 \%$ of these tumors are malignant [1,2]. So far, many studies have been performed to determine the prognosis and the malignancy of mammary cancers of dogs and humans by examining clinical parameters [2-9].

Matrix metalloproteinases )MMPs( are a family of zinc- and calcium-dependent proteolytic enzymes that involve in the degradation and remodeling of extracellular matrix [10]. These enzymes are expressed by various types of tissue cells under physiological conditions $[11,12]$. Proteolytic degradation of the extracellular matrix and angiogenesis are associated with tumor invasion and metastasis in human and dog neoplasia [11]. It has been observed that canine adenocarcinoma and benign tumor mammary tissues have 426 and 1-6 times higher levels of $92 \mathrm{kDa}$ MMP-9 than that of control tissues, respectively. In addition, MMP 9 concentration in neoplasm of the dog is much more than the surrounding normal tissues [13]. It has been shown that MMP-2 and MMP-9 are expressed on tumor cells of the canine and human mammary neoplasm $[1,14-16]$. In human breast cancer, MMP-2 and MMP-3 in breast carcinoma have been shown to be expressed by peritumoral stromal cells in addition to tumor cells [16]. Moreover, in canine mammary carcinomas, MMP-2 was mainly expressed in the cytoplasm of carcinoma cells and in fibroblasts [15].Also, MMP-9 is expressed by vascular pericytes and stromal cells in addition to tumor cells, and when cocultured with breast cancer cells, 
normal fibroblasts secrete MMP-9. Other major sources of MMP-9 in tumors are: inflammatory cells like mast cells, monocyte-macrophages, and tumor-infiltrating leukocytes [16].

Increased gelatinase levels in the tumor and serum may be consistent with tumor invasion. Therefore, pathology along with the measurement of MMPs in serum has been recommended for the prognosis of metastasis and recurrence of the tumor [17]. The diagnostic value of serum levels of MMPs concentration has been confirmed for subtyping of breast cancer in humans [18].

Regarding the role of MMP-2 and MMP-9 in the progression, metastasis, and prognosis of tumors in dogs, and the high value of gelatin zymography method in determining the activity of these enzymes $[17,18]$, we decided to determine serum levels of the gelatinases in mammary tumors to determine their value in diagnosing malignancy or benign tumors as well as in predicting the possibility of metastasis and recurrence. Frequent measurement of MMP-2 and MMP-9 by gelatin zymography in serum before and after surgical treatment, has not been previously studied to monitor the mammary tumors in dogs. The results of this study can be helpful in determining the malignancy of mammary tumors and their prognosis.

\section{Materials And Methods}

Forty dogs with different types of mammary tumors were evaluated at the Veterinary Teaching and Research Hospital of Faculty of Veterinary Medicine, University of Tehran and Paytakht Pet Hospital from April 2015 to March 2018. Finally, 26 dogs with mammary tumors were selected that did not have any chronic diseases such as chronic heart failure, chronic kidney problems, and endocrine diseases based on their history, clinical examination, and hematology and clinical biochemistry tests. Then, patients were examined for the involvement of lymph nodes. Radiological examination of the chest and abdominal ultrasound were performed to determine the probability of metastasis. Surgical treatment was selected for all types of tumors and the removed tissues were fixed in formalin $10 \%$. Ovariohysterectomy was also performed during the surgical removal of breast masses. On the day of surgery (preoperative), blood samples were collected into tubes without anticoagulant for serum separation. Serum was prepared and the samples were stored at $-70^{\circ} \mathrm{C}$ immediately after collection to be used later for zymography. Additionally, 26 healthy adult female dogs with a similar breed, age, and weight to the patient group were selected as control. All examinations that were performed on the patients were done on these cases as well.

\section{Pathology}

The tissue samples were embedded in paraffin and then tissue sections were prepared at 4 micrometers and placed on a slide. The usual staining of hematoxylin and eosin (H\&E) was performed. The slides were examined with optical microscopy and pathologic parameters based on the criteria mentioned in sources and they were diagnosed according to the specific cytological findings. Mammary tumors were categorized to malignant and benign type [19-22]. Maxie's criteria were used to determine the grade of malignancy [21]. Pathological parameters including necrosis, mode of growth, stromal invasion and mitotic index were evaluated. Also, patients were examined for involvement of lymph nodes.

\section{Serum gelatin zymography}


Serum samples of surgical day, one month, four months and 1 year after surgical treatment were evaluated to determine the level of active and inactive MMP-2 and MMP-9 by gelatin zymography protocol $[23,24]$.

\section{Follow-up study of patients}

The duration of this study was 36 months and the condition of patients with the mammary tumor was monitored during this time. Thus, patients were examined every 4 months and in each visit, tumor recurrence was evaluated by abdominal ultrasonography and chest radiography and information was recorded.

\section{Statistical analyses}

The findings of preoperative, one month, four months and one year after surgery in two groups with $M / R$ and no M/R were statistically compared using the one-way repeated measures ANOVA. In addition, the results of the first day of zymography were analyzed by one-way ANOVA to compare the malignant, benign tumors and control groups. To evaluate the prognosis of patients, the overall survival time (OS) (from surgical removal to the patient's death) and disease-free survival time (DFS) (from surgical treatment of the tumor to the first $\mathrm{M} / \mathrm{R}$ ) were calculated for malignant mammary tumors using the Kaplan-Meier statistical method and the logrank analysis obtained the differences between groups (with /no M/R). For each variable, the risk of recurrence or distant metastasis (pulmonary metastasis) and the risk of death associated with the tumor were estimated by Cox regression analysis. In order to select outcome predictors, significant variables related to OS or DFS in univariate analysis were also studied in the multivariate Cox's proportional hazards model (forward stepwise) to control the confounding variables. The cut-off point of serum MMPs was defined by the Roc curves. All statistical tests were performed using SPSS software and data were expressed as the mean and standard error (SE). The significance level ( $p$-value) in all statistical tests was less than or equal to 0.05 .

\section{Results}

\section{Pathological parameters}

As shown in table 1, nine tubulopapillary carcinomas (34.6\%), three complex carcinomas (11.6\%), two papillary carcinomas $(7.7 \%)$, two solid carcinomas $(7.7 \%)$, one simple carcinoma $(3.8 \%)$, one inflammatory carcinoma (3.8\%), 2 cases of lobular hyperplasia $(7.7 \%)$ and six benign mix tumors $(23.1 \%)$ were diagnosed. Therefore, out of 26 observed mammary tumors, 18 (69.23\%) were observed as malignant tumors and 8 $(30.76 \%)$ as benign tumors.

In dogs with malignant tumors, $66.66 \%$ of cases showed M/R and $55.55 \%$ of them died. While $37.5 \%$ of patients with benign tumors showed $M / R$ but were still alive until the end of the study period.

As shown in table 2, in dogs with malignant mammary tumors, the presence of necrosis, infiltrative growth, and stromal invasion significantly reduced the DFS and OS. However, the presence of necrosis (HR: 12.46; 95\% Cl: 2.47-26.83; $P=0.002$ ), infiltrative growth (HR: 21.82; 95\% Cl: 2.65-29.4; $P=0.004$ ), and stromal invasion (HR: 21.82; 95\% Cl: 2.65-29.4; $P=0.004$ ) were significantly considered the risk for $\mathrm{M} / \mathrm{R}$ in malignant mammary tumors of the dogs. In addition, the presence of necrosis (HR: $12.55 ; 95 \% \mathrm{Cl}: 2.49-33.21 ; P=0.002$ ) was significantly associated with death. 
Although, lymphocyte infiltration in malignant tumor decreased DFS and OS significantly and increased pulmonary metastasis and recurrence, only grade 2 lymphocyte infiltration was a significant risk factor compared to other grades for M/R (HR: $0.036 ; 95 \% \mathrm{Cl}: 0-0.38 ; P=0.006)$ and death (HR: $0.1 ; 95 \% \mathrm{Cl}: 0.01-0.94$; $P=0.045)$ in dogs with malignant mammary tumors. The histology grade of malignant mammary tumors and mitotic index in dogs did not significantly affect the DFS and OS (table 2).

Meanwhile, M/R and death were observed significantly faster in dogs with lymph nodes metastasis (LNM),but only LNM increase with DFS was a risk factor in the Cox regression analysis (HR: $21.82 ; 95 \% \mathrm{Cl}$ : 2.65-19.44; $P=0.004$ ) but LNM increase with OS was not a risk factor (HR: 13.54; 95\% Cl: 0.9-13.94; $P=0.07$ ). In addition, dogs with inguinal lymph node metastasis had significantly shorter OS than axillary cases, although it was not found to be a risk factor (HR: 3.61;95\% Cl: 1.82-22.42; $P=0.242)$. Two cases of metastasis to the lung are shown in Fig. 1.

\section{Serum gelatin zymography}

Semiquantitative analysis of zymograms from dog serums indicates that only Pro-MMP-2 (72 kDa) and ProMMP-9 (92 kDa) bands appeared in the control group. Furthermore, on the day of surgery, dogs with benign and malignant mammary tumors showed bands of Pro-MMP-2, Pro-MMP-9 and active MMP-9 (82 kDa), respectively. Fig. 2-A shows serum gelatin zymography of a dog with benign mixed tumor without M/R. It should be noted that similar to the control group, two patients with benign lobular hyperplasia tumor left the only Pro-MMP-2 and Pro-MMP-9 in the gel. In the preoperative samples, only one case of inflammatory carcinoma revealed the active form of MMP-2 with molecular weight of $66 \mathrm{kDa}$. The patient eventually showed pulmonary metastasis seven months after the surgery, and in the next year, the active form of MMP-2 with molecular weight of $62 \mathrm{kDa}$ was detected in the gel. Fig. 2-B shows serum gelatin zymography of a dog with inflammatory carcinoma with $M / R$.

As shown in table 3 statistical analysis of zymograph data in preoperative samples showed a significant increase in Pro-MMP-2 levels in patients with malignant mammary tumors compared with patients with benign mammary tumors and the control group. The observed increase is 2 times compared to the control group. Also, a significant increase in Pro-MMP-9 levels was observed in patients with malignant tumors only compared to the control group. Moreover, the increase in active MMP-9 levels in patients with benign and malignant tumors compared to the control group was significant, but no significant difference was observed between the levels of Pro-MMP-9 and active MMP-9 in the group of benign and malignant tumors.

One month after surgical treatment, the active form of MMP-9 appeared in nine cases of malignant tumors, seven cases of which were recurred or metastasized during the period of study but two cases did not experience M/R by the end of the study (36 months after surgery). At the same time, the active band of MMP-2 was not observed in any of the samples .Also, in the four months after surgery, six cases of malignant tumors revealed the active MMP-9, all of which represented M/R. Furthermore, after one year of surgical treatment, 12 cases showed active MMP-9 and eight cases active MMP-2 bands with molecular weight of $62 \mathrm{kDa}$ (five cases) and $66 \mathrm{kDa}$ (three cases), all of which had M/R.

As shown in Fig. 3, in dogs with mammary tumors that were metastasized or recurred, serum concentration of Pro-MMP-2 was decreased significantly one month after surgery compared to the preoperative sample. On the 
other hand, a significant increase in the levels of Pro-MMP-2 was observed in serum samples of 4 and 12 months after surgery in comparison to one month after surgery $(P \leq 0.05)$. The active form of MMP-2 showed a significant increase in the M/R group 12 months after surgery compared with the day of surgery, 1 and 4 months after surgery $(P \leq 0.05)$. One and four months after surgery, there were no significant changes in serum levels of Pro-MMP-9 in M/R dogs compared to the day of surgery $(P \geq 0.05)$, but a significant increase in its concentrations was observed 12 months after surgery than the other sampling times $(P \leq 0.05)$. Serum active MMP-9 in the M/R group had a significant decrease in 1, 4, and 12 months after surgery compared to the day of surgery, while in the 12-month follow-up sampling, its activity showed significant increases than 1 and 4 months after surgery $(P \leq 0.05)$.

However, in without M/R group, the changes in Pro -MMP-2 and Pro-MMP-9 levels on the day of surgery and sampling times were not significant and only the amounts of active MMP-9 observed in one month after surgery showed a significant decrease compared to the day of surgery. In addition, active MMP-9 band was not observed in other sampling times (Fig.3).

As shown in table 4, in dogs with serum Pro-MMP-2 levels of more than $1.5 \mathrm{ng} / \mathrm{lane}, \mathrm{M} / \mathrm{R}$ and death were seen $77.8 \%$ and $66.7 \%$, respectively. While for dogs whose serum Pro-MMP-2 was less than $1.5 \mathrm{ng} / \mathrm{lane}, 47 \% \mathrm{M} / \mathrm{R}$ and $23.5 \%$ death were observed. Regarding Pro-MMP-9, dogs with serum Pro-MMP-9 levels greater than 0.9 $\mathrm{ng} / \mathrm{lane}, 66.7 \%$ had M/R and died but in dogs with Pro-MMP-9 less than $0.9 \mathrm{ng} / \mathrm{lane}, \mathrm{M} / \mathrm{R}$ and death were observed $50 \%$ and $14.3 \%$ respectively. Meanwhile, $73.3 \% \mathrm{M} / \mathrm{R}$ and $46.7 \%$ death were seen in dogs with more than $1.8 \mathrm{ng} /$ lane serum active MMP-9 concentrations, but in the group with active MMP-9 less than 1.8 $\mathrm{ng} /$ lane, M/R and death were observed $36.4 \%$ and $27.3 \%$, respectively. Also, dogs with mammary tumors that had a serum Pro-MMP-2 level of more than $1.5 \mathrm{ng} /$ lane had a faster DFS and less OS. However, only their OS showed a significant difference with the group less than $1.5 \mathrm{ng} / \mathrm{lane}$ (HR: $3.62 ; 95 \% \mathrm{Cl}: 1.01-12.97 ; \mathrm{P}=0.048$ ). Besides, Faster DFS and lower OS were observed in dogs with serum Pro-MMP-9 levels greater than 0.9 ng/lane, but only OS was statistically significant (HR: 6.08; $95 \% \mathrm{Cl}: 1.29-28.72 ; \mathrm{P}=0.023)$. Regarding serum active MMP-9, dogs whose serum active MMP-9 was more than $1.8 \mathrm{ng} /$ lane had faster DFS and shorter OS than those with less than $1.8 \mathrm{ng} /$ lane, however, the differences were not significant.

\section{Discussion}

Pathological evaluations are widely used today to diagnose benign and malignant mammary tumors. Other methods should be used to evaluate and predict metastasis and recurrence of the disease [21]. Our previous research has shown that serum evaluation of MMP-2 and MMP-9 by zymography may be helpful for the prognosis of metastasis and recurrence of canine cutaneous [23] and intrascrotal hemangiomas tumors [24]. Therefore, in this study, we decided to investigate the role of serum MMP-2 and MMP-9 in metastasis and recurrence in dogs with mammary tumors before and after surgery.

Our study showed that in the first sampling (before surgery) to diagnose benign and malignant tumors, pathological evaluation is preferable to MMPs measurement except that Pro-MMP-2 levels increased more dramatically ( 2 fold) in malignant tumors than in benign and control groups. Although, Aresu et al (2011) described that high plasma levels of Pro-MMP-2 and Pro-MMP-9 were observed in dogs with mammary adenoma and carcinoma without any differences in levels between malignant and benign tumors ${ }^{1}$. 
In present study, zymography results showed that serum Pro-MMP-2 and Pro-MMP-9 levels greater than 1.5 (with Hazard ratio 3.62) and 0.9 (with Hazard ratio 6.08) ng/lane levels respectively are risk factors for death in dogs with mammary tumors.

Loukopoulos et al (2003) identified Pro-MMP-2(72kDa), the active form of MMP-2 (62 and 66kDa) and Pro MMP-9 (92kDa) in the tumor tissue of various neoplasms in dogs [12]. Moreover, Aresu et al (2011) observed Pro-MMP-2, Pro-MMP-9, and active MMP-9 in the plasma of all dogs with benign and malignant mammary tumors but the active form of MMP-2 was not found in either case [1]. In current study, in benign tumors except lobular hyperplasia, the Pro- MMP-2 and Pro-MMP-9 and the active form of MMP-9(82kDa) were observed. Patients with benign lobular hyperplasia left the only Pro-MMP-2 and Pro-MMP-9 in the gel on surgery day and all times sampling. The active form of MMP-2 did not appear in the recurred benign tumors as well. Five and three malignant tumors with recurrence or pulmonary metastasis revealed the active form of MMP-2 with a molecular weight of 62 and $66-k D a$ respectively.

Loukopoulos et al (2003) reported that active MMP-9 plays a less important role in tumor progression and metastases, because active MMP-9 was found in a very small number of tumor tissues [12].But, Aresu et al (2011) observed no significant difference in the plasma concentration of active form of MMP-9 between malignant and benign tumors. They reported that MMP-9 plasma levels could be consistent with MMP-9 protease activity $^{1}$. The higher serum levels of MMP-9 activity have been detected in dogs with mammary adenocarcinoma and, possibly, this type of MMP may play an important role in the early stage of adenocarcinoma [13].Our findings showed that the presence of active MMP-9 (especially in samples 4 and 12 months after surgery for malignant tumors), regardless of its amount, is important in terms of prognosis for $M / R$, compared to the group without $M / R$.

Also, Loukopoulos et al (2003) reported that Zymographic detection of the active MMP-2(62 kDa) was linked with the malignant phenotype and only metastatic malignancies produced the $62 \mathrm{kDa}$ form of active MMP-2 [12].Moreover, Aresu et al (2011) described that the active form of MMP-2 was not found in the plasma of all dogs with benign and malignant mammary tumors [1]. But in our study, observation of active MMP-2 (62 or $66 \mathrm{kDa}$ ) band is very important for M/R than active MMP-9 because its presence regardless of their values coincides with a definite recurrence and metastasis, unlike the active form of MMP-9. However, it should be noted that the absence of active MMP-2 form does not rule out the recurrence and metastasis in patients with mammary tumors.

Research in rat with mammary adenocarcinoma showed that serum levels of 92-kDa progelatinase (precursor of MMP-9) were associated with the development of metastases in the lungs and lymph nodes. The findings indicated that high levels of Pro-MMP-9 in plasma and serum are associated with the presence of metastatic adenocarcinoma cells [25]. Also, regarding pro-MMP-9 in M/R dogs, our findings showed a significant increase in the levels of Pro-MMP-9 in serum samples 12 months after surgery compared with other sampling times. Therefore, this enzyme may facilitate the blood invasion of tumor cells through the vascular membrane [25].

Research shows that in many cancers, some MMPs like MMP-2 and MMP-9 are more abundantly expressed by stromal cells than by tumor cells in which they have a role to important changes in the tumor microenvironment [26]. Research by Blavier et al (2006) showed that during the early and later stages of tumor 
formation and stages of tumor progression, MMP-2 and MMP-9 which were frequently expressed in the stroma of tumor, may also contribute in stimulating endothelial cell transformation and growth [16]. Santos et al (2013) described that the expressions of MMP-9 by stromal cells and of Ki-67 by cancer cells are independent prognostic factors in canine malignant mammary tumors. Also, they stated that mentioned parameters showed a stronger prognostic value than histological or clinical factors routinely used to predict patient's outcome, such as tumor size, histological grade and mode of growth [2].

Our results showed that metastasis to the lymph nodes reduces the time of DFS, OS and increases the risk of $M / R$, which had previously been reported in human [9]. In addition, veterinary research suggested that lymph node involvement was associated with poor prognosis of canine mammary tumor $[5,8]$.

Based on the findings of this study, tissue necrosis and invasion due to the infiltrative growth of malignant mammary tumors in dogs significantly increased the rate of $M / R$ and decreased the time of survival in affected dogs. Necrosis, stromal invasion, and infiltrative growth increase risk of the development of $M / R$ and the presence of necrosis is a risk factor for death. Necrosis has been suggested as an indicator for the promotion of tumor invasion [6-8].

In our study, the infiltration of lymphocytes into malignant mammary tumors in dogs was identified as a risk factor for metastasis, recurrence and death. The functional role of infiltrating lymphocytes in breast tumors has not yet been fully understood. However, it has been shown that the percentage of $T$ lymphocytes was significantly higher in dogs with malignant mammary carcinoma and mixed mammary tumors without metastasis, which indicates a protective role in preventing tumor progression [3].

According to our findings, the histology grade of mammary tumors and mitotic index in dogs did not significantly affect the time of $M / R$ and survival. Nevertheless, some studies suggested that dogs with grade II and III carcinoma had less survival time [4] and mammary tumors with grade III have a shorter OS time and high risk of death [2]. However, the differences between our results and other researchers may be related to the number of cases and types of tumors examined, moreover, the time of patient's referral to the surgeon should not be ignored. It seems that more research is needed in this regard.

In conclusion, it may be possible to use zymography of serum samples at specific intervals after surgery to examine the probability of recurrence or metastasis.

\section{Declarations}

\section{Ethics approval and consent to participate}

In this study, only animals (dogs with mammary tumors and control dogs) were touched and involved and no humans were sampled or touched. All methods were performed in accordance with the relevant guidelines and regulations. All phases of this study were approved by the Animal Care Committee of the University of Tehran (No.7508017.6.18). Written informed consent was obtained from the dog owners for their dogs to be used in this study. This article does not contain any experimental studies with animals.

\section{Consent for publication}


Not applicable

\section{Availability of data and materials}

The data used and/or analysed during the current study are available from the corresponding author on reasonable request.

\section{Competing interests}

The authors declare that they have no potential conflicts of interest with respect to the research, authorship, and/or publication of this article.

\section{Funding}

This study was financially supported by the Research Deputy of the University of Tehran.

\section{Authors' contributions}

ZK and VF conceptualized the study, performed the experiments. VF analysed the data. ZK and VF drafted and revised the manuscript. All authors read, edited and approved the final manuscript.

\section{Acknowledgments}

We appreciate Dr. Seyyed Mehdi Nassiri at the Faculty of Veterinary Medicine, University of Tehran for his valuable contributions. The authors wish to thank the staff of the Dr. Rastegar laboratory and Paytakht Pet Hospital to cooperate in this study.

\section{Authors' information}

Corresponding author: Vahid Fathipour: PO Box: 14686-63663 No.131, Blv.Dadman, Shahrk gharb, Tehran, Iran. Email address: Vahid.vet83@gmail.com, Fax number: +982188368585, Telephone number: +989104571085, +982166517825. ORCID Number: 0000-0001-8999-8433

Zohreh Khaki: PO Box: 14155-6453, University of Tehran, Faculty of Veterinary Medicine, Qareeb Street, Azadi Avenue, Tehran, Iran. Email address: zkhaki@ut.ac.ir, Fax number: +982196333222, Telephone number: +989122905571, +982161117084.

\section{References}

1. Aresu L, Giantin M, Morello E, Vascellari M , Castagnaro M, Lopparelli R, Zancanella V, Granato A, Garbisa S , Aricò A, Bradaschia A, Mutinelli F , Dacasto M (2011) Matrix metalloproteinases and their inhibitors in canine mammary tumors. BMC Vet Res 7: 33.

2. Santos AA, Lopes CC, Ribeiro JR, Martins LR, Santos JC, Amorim IF, Gärtner F, Matos AJ (2013) Identification of prognostic factors in canine mammary malignant tumours: a multivariable survival study. BMC Vet Res 9: 1. 
3. Estrela-Lima A, Araújo MS, Costa-Neto JM, Teixeira-Carvalho A, Barrouin-Melo SM, Cardoso SV, MartinsFilho OA, Serakides R, CassaliGD (2010) Immunophenotypic features of tumor infiltrating lymphocytes from mammary carcinomas in female dogs associated with prognostic factors and survival rates. BMC cancer 10: 256.

4. Karayannopoulou M, Kaldrymidou E, Constantinidis TC, Dessiris A (2005) Histological grading and prognosis in dogs with mammary carcinomas: application of a human grading method. J com path 133 : 246-252.

5. Yamagami T, Kobayashi T, Takahashi K, Sugiyama M (1996) Prognosis for canine malignant mammary tumors based on TNM and histologic classification. J Vet Med Sci 58: 1079-1083.

6. Alenza MDP, Pena L, Nieto Al, Castano M (1997) Clinical and pathological prognostic factors in canine mammary tumors. Ann Ist Super Sartltti 33: 581-585.

7. De Las Mulas JM, Millán Y, Dios R (2005) A prospective analysis of immunohistochemically determined estrogen receptor $a$ and progesterone receptor expression and host and tumor factors as predictors of disease-free period in mammary tumors of the dog. Vet pathol 42: 200-212.

8. Hellmén E, Bergström R, Holmberg L, Spångberg IB, Hansson K, Lindgren A (1993) Prognostic factors in canine mammary tumors: a multivariate study of 202 consecutive cases. Vet Pathol 30: 20-27.

9. Todd JH, Dowle C, Williams MR, Elston CW, Ellis IO, Hinton CP, Blamey RW, Haybittle JL(1987) Confirmation of a prognostic index in primary breast cancer. Brit J cancer. 56: 489-492.

10. Chegeni S, Khaki Z, Shirani D, Vajhi A, Taheri M, Tamrchi Y, Rostami A (2015) Investigation of MMP-2 and MMP-9 activities in canine sera with dilated cardiomyopathy. Iran J Vet Res 16:182-187.

11. Giantin M, Aresu L, Benali, Arico A, Morello EM, Martano M, Vascellari M, Castagnaro M, Lopparelli RM, Zancanella V, Granato A, Mutinelli F, Dacasto M (2012) Expression of matrix metalloproteinases, tissue inhibitors of metalloproteinases and vascular endothelial growth factor in canine mast cell tumours. J Comp Pathol 147: 419-429.

12. Loukopoulos P, Mungall BA, Straw RC, Thornton JR, Robinson WF(2003) Matrix metalloproteinase-2 and9 involvement in canine tumors. Vet Pathol 40: 382-394.

13. Yokota H, Kumata T, Taketaba S, Kobayashi T,Moue H, Taniyama H, Hirayama K, Kagawa Y, Itoh N, Fujita O, Nakade T, Yuasa A (2001) High expression of 92-kDa type IV collagenase (matrix metalloproteinase-9) in canine mammary adenocarcinoma. Biochim Biophys Acta. 1568: 7-12.

14. Hirayama K, Yokota H, Onai R, Kobayashiy T, Kumata T, Kihara K, Okamoto M , Sako T, Nakade T, Izumisawa Y, Taniyama H (2002) Detection of matrix metalloproteinases in canine mammary tumours: analysis by immunohistochemistry and zymography. J comp pathol. 127: 249-256.

15. Papparella S, Restucci B, Paciello O, Maiolino P (2002) Expression of matrix metalloprotease-2 (MMP-2) and the activator membrane type 1 (MT1-MMP) in canine mammary carcinomas. J Comp Pathol. 126: 271-276.

16. Blavier L, Lazaryev A, Dorey F ,Shackleford GM, DeClerck YA(2006).Matrix Metalloproteinases Play an Active Role in Wnt1-Induced Mammary Tumorigenesis. Camcer Research, 66:2691-2699.

17. Kanako MIYA, Misumi K, Miyoshi N, Arai K, Fujiki M, Kubota C, Sakamoto H (2005) Interpreting gelatinase activity in tumor tissue and serum as a prognostic marker of naturally developing canine tumors. J Vet 
Med Sci. 67: 769-775.

18. La Rocca G, Pucci-Minafra I, Marrazzo A, Taormina P, Minafra S (2004) Zymographic detection and clinical correlations of MMP-2 and MMP-9 in breast cancer sera. Brit J Cancer 90: 1414-1421.

19. Goldschmidt MH, Peña L, Zappulli V (2016) Tumors of the mammary gland. In: Meuten D J Tumors in domestic animals, 5th eds. John Wiley \& Sons, Raleigh , 723-765.

20. Goldschmidt M, Pena L, Rasotto R, Zappulli V (2011) Classification and grading of canine mammary tumors. Vet Pathol 48: 117-131.

21. Schlafer DH, Foster RA (2015) Female Genital System. In: Maxie MG Jubb, Kennedy \& Palmer's Pathology of Domestic Animals. 6th eds, Elsevier, Ontario, 459-463.

22. Sorenmo KU, Worley DR, Goldschmidt MH (2013) Tumors of the Mammary Gland. In: Withrow SJR and Vail DM Withrow and MacEwen's small animal clinical oncology. 5th eds, Elsevier, Colorado, 538-556.

23. Fathipour V, Khaki Z, Nassiri SM (2018) Evaluation of matrix metalloproteinases (MMP)-2 and MMP-9 activity in serum and biochemical parameters in spontaneous canine cutaneous tumors before and after surgical treatment. Vet Res Forum 9: 19-26.

24. Fathipour V, Khaki Z, Nassiri SM, Taheri M (2020) Prognostic value of zymographic gelatinase activity of MMP-2 and MMP-9 in tumor recurrence of canine intrascrotal hemangiomas. Com clin Path 29: 25-31.

25. Nakajima M, Welch DR, Wynn DM, Tsuruo T, Nicolson GL (1993) Serum and plasma Mr 92,000 progelatinase levels correlate with spontaneous metastasis of rat 13762NF mammary adenocarcinoma. Cancer Res 53: 5802-5807.

26. Almholt K, Johnsen M (2003) Stromal cell involvement in cancer. Recent Results Cancer 162:31-42.

\section{Tables}

Table1 .Histopathological classification of mammary tumors in dogs and description of tumor types with $\mathrm{M} / \mathrm{R}$ and mortality rate 


\begin{tabular}{|cllllll|}
\hline & \multicolumn{2}{l}{ Tumors } & \multicolumn{2}{l}{ M/R } & \multicolumn{2}{l|}{ Dead or euthanized dogs } \\
\hline & N & $\%$ & N & $\%$ & N & $\%$ \\
\hline Total number & 26 & 100 & 15 & 57.69 & 10 & 38.46 \\
\hline Malignant tumors & 18 & 69.23 & 12 & 66.66 & 10 & 55.55 \\
\hline Tubulopapillary carcinomas & 9 & 34.6 & 6 & 66.7 & 5 & 55.5 \\
\hline Complex carcinomas & 3 & 11.6 & 1 & 33.3 & 1 & 33.3 \\
\hline Papillary carcinomas & 2 & 7.7 & 1 & 50 & 0 & 0 \\
\hline Solid carcinomas & 2 & 7.7 & 2 & 100 & 2 & 100 \\
\hline Simple carcinoma & 1 & 3.8 & 1 & 100 & 1 & 100 \\
\hline Inflammatory carcinoma & 1 & 3.8 & 1 & 100 & 1 & 100 \\
\hline Benign tumors & 8 & 30.76 & 3 & 37.5 & 0 & 0 \\
\hline Lobular hyperplasia & 2 & 7.7 & 0 & 0 & 0 & 0 \\
\hline Benign mix tumors & 6 & 23.1 & 3 & 50 & 0 & 0 \\
\hline
\end{tabular}

Table 2. The association between studied histopathological variables in malignant mammary tumor in dogs with DFS and OS 


\begin{tabular}{|c|c|c|c|c|c|c|c|c|c|c|}
\hline \multirow[t]{2}{*}{ Variables } & \multicolumn{2}{|c|}{ Animals } & \multicolumn{2}{|c|}{$M / R$} & \multirow{2}{*}{$\begin{array}{l}\text { Tme of } \\
\text { DFS } \\
\text { (months) } \\
\text { Mean } \pm \\
\text { SE }\end{array}$} & \multirow[t]{2}{*}{$\mathrm{P}^{\mathrm{b}}$} & \multicolumn{2}{|c|}{$\begin{array}{l}\text { Dead or } \\
\text { euthanized dogs }\end{array}$} & \multirow{2}{*}{$\begin{array}{l}\text { Time of } \\
\text { OS } \\
\text { (months) } \\
\text { Mean } \pm \\
\text { SE }\end{array}$} & \multirow[t]{2}{*}{$P$} \\
\hline & $\mathbf{N}$ & $\%$ & $\mathbf{N}$ & $\%$ & & & N & $\%$ & & \\
\hline $\begin{array}{l}\text { Total } \\
\text { number }\end{array}$ & 18 & 100 & 12 & 66.66 & $\begin{array}{l}9.16 \pm \\
0.90\end{array}$ & & 10 & 55.55 & $10.1 \pm 1$ & \\
\hline \multicolumn{11}{|c|}{ Histopathological variables } \\
\hline Necrosis & & & & & & 0.000 & & & & 0.000 \\
\hline Yes & 8 & 44.4 & 8 & 100 & $\begin{array}{l}7.87 \pm \\
0.91\end{array}$ & & 8 & 100 & $\begin{array}{l}18.12 \pm \\
0.83\end{array}$ & \\
\hline No & 10 & 55.6 & 4 & 40 & $\begin{array}{l}26.30 \pm \\
3.87\end{array}$ & & 2 & 20 & $\begin{array}{l}32.80 \pm \\
2.02\end{array}$ & \\
\hline $\begin{array}{l}\text { Mode of } \\
\text { growth }\end{array}$ & & & & & & 0.000 & & & & 0.000 \\
\hline Infiltrative & 10 & 55.5 & 10 & 100 & $\begin{array}{l}8.40 \pm \\
0.88\end{array}$ & & 10 & 100 & $\begin{array}{l}18.50 \pm \\
0.71\end{array}$ & \\
\hline Expansive & 8 & 44.5 & 2 & 25 & $\begin{array}{l}30.25 \pm \\
3.39\end{array}$ & & 0 & 0 & $\begin{array}{l}31.12 \pm \\
1.51\end{array}$ & \\
\hline $\begin{array}{l}\text { Histological } \\
\text { grade }\end{array}$ & & & & & & 0.616 & & & & 0.997 \\
\hline Grade I+II & 2 & 11.1 & 1 & 50 & $\begin{array}{l}19.50 \pm \\
6.71\end{array}$ & & 1 & 50 & $\begin{array}{l}26.50 \pm \\
3.88\end{array}$ & \\
\hline Grade III & 16 & 88.9 & 11 & 68.7 & $\begin{array}{l}17.50 \pm \\
3.18\end{array}$ & & 9 & 56.2 & $\begin{array}{l}26.18 \pm \\
2.20\end{array}$ & \\
\hline $\begin{array}{l}\text { Stromal } \\
\text { invasion }\end{array}$ & & & & & & 0.000 & & & & 0.000 \\
\hline Yes & 10 & 55.5 & 10 & 100 & $\begin{array}{l}8.40 \pm \\
0.88\end{array}$ & & 10 & 100 & $\begin{array}{l}18.50 \pm \\
0.71\end{array}$ & \\
\hline No & 8 & 44.5 & 2 & 25 & $\begin{array}{l}30.25 \pm \\
3.39\end{array}$ & & 0 & 0 & $\begin{array}{l}31.12 \pm \\
1.51\end{array}$ & \\
\hline Mitotic index & & & & & & 0.157 & & & & 0.187 \\
\hline $\begin{array}{l}\text { 10-19/10 } \\
\text { HPF }\end{array}$ & 10 & 55.5 & 6 & 60 & $\begin{array}{l}21.10 \pm \\
3.87\end{array}$ & & 4 & 40 & $\begin{array}{l}29.00 \pm \\
2.73\end{array}$ & \\
\hline$\leq 20 / 10 \mathrm{HPF}$ & 8 & 44.5 & 6 & 75 & $\begin{array}{l}14.37 \pm \\
4.47\end{array}$ & & 6 & 75 & $\begin{array}{l}22.87 \pm \\
2.77\end{array}$ & \\
\hline $\begin{array}{l}\text { Lymphocyte } \\
\text { infiltration }\end{array}$ & & & & & & 0.002 & & & & 0.043 \\
\hline Grade 0 & 1 & 5.6 & 0 & 0 & - & & 0 & 0 & - & \\
\hline Grade 1 & 6 & 33.3 & 1 & 16.7 & $32.16 \pm$ & & 1 & 16.7 & $33.50 \pm$ & \\
\hline
\end{tabular}




\begin{tabular}{lllllllll} 
Grade 2 & 7 & 38.9 & 7 & 100 & $\begin{array}{l}9.28 \pm \\
1.20\end{array}$ & 5 & 71.4 & $22.57 \pm$ \\
& & & & & & & 3.26 \\
\hline Grade 3 & 4 & 22.2 & 4 & 100 & $\begin{array}{l}8.00 \pm \\
1.47\end{array}$ & 4 & 100 & $19.50 \pm$ \\
& & & & & & & & 0.86
\end{tabular}

\begin{tabular}{|c|c|c|c|c|c|c|c|c|}
\hline \multicolumn{3}{|l|}{ LNM $^{a}$} & \multicolumn{6}{|c|}{0.000} \\
\hline Yes & 10 & 55.5 & 10 & 100 & $\begin{array}{l}8.40 \pm \\
0.88\end{array}$ & 10 & 100 & $18.50 \pm$ \\
\hline
\end{tabular}

$\begin{array}{lllllllll}\text { No } & 8 & 44.5 & 2 & 25 & \begin{array}{l}30.25 \pm \\ 3.39\end{array} & 0 & 0 & 31.12 \pm \\ & & & & & & \end{array}$

Involved LN $\quad 0.283$

$\begin{array}{llllllllll}\text { Inguinal } & 8 & 80 & 8 & 100 & \begin{array}{l}8.00 \pm \\ 0.90\end{array} & 8 & 100 & 17.87 \pm \\ & & & & & & & & 0.74\end{array}$

$\begin{array}{lllllllll}\text { Axillary } & 2 & 20 & 2 & 100 & \begin{array}{l}10.00 \pm \\ 3.00\end{array} & 2 & 100 & 21.00 \pm \\ & & & & & & & & 0.00\end{array}$

aLymph Node Metastasis b bog Rank test

Table 3. Mean \pm SE value of serum levels of MMPs between dogs with benign and malignant mammary tumors and the control group (preoperative)

\begin{tabular}{|c|c|c|c|c|c|c|}
\hline \multirow{2}{*}{$\begin{array}{l}\text { Parameter } \\
\text { (ng/lane) }\end{array}$} & \multirow{2}{*}{$\begin{array}{l}\text { Control } \\
\text { (C) }\end{array}$} & \multirow{2}{*}{$\begin{array}{l}\text { Benign tumors } \\
(B)\end{array}$} & \multirow{2}{*}{$\begin{array}{l}\text { Malignant tumors } \\
\text { (M) }\end{array}$} & \multicolumn{3}{|c|}{$P^{*}$} \\
\hline & & & & C-M & C-B & M-B \\
\hline Pro-MMP-2 & $\begin{array}{l}0.68 \pm \\
0.05\end{array}$ & $0.92 \pm 0.07$ & $1.45 \pm 0.06$ & 0.000 & 0.052 & 0.000 \\
\hline & & & & 0.002 & 0.176 & 0.653 \\
\hline Pro-MMP-9 & $\begin{array}{l}0.66 \pm \\
0.05\end{array}$ & $0.84 \pm 0.02$ & $0.94 \pm 0.06$ & & & \\
\hline Active MMP-9 & 0 & $1.65 \pm 0.37$ & $1.83 \pm 0.12$ & 0.000 & 0.000 & 0.674 \\
\hline
\end{tabular}

* One-way ANOVA; C, Control; B, Benign; M, Malignant 
Table 4. The association between zymography parameters (surgery day) in canine mammary tumor with DFS and OS

\begin{tabular}{|c|c|c|c|c|c|c|c|c|c|c|}
\hline \multirow[t]{2}{*}{ Variables } & \multicolumn{2}{|c|}{ Animals } & \multicolumn{2}{|c|}{$M / R$} & \multirow{2}{*}{$\begin{array}{l}\begin{array}{l}\text { DFS } \\
\text { (months) }\end{array} \\
\text { Mean } \pm \\
\text { SE }\end{array}$} & \multirow[t]{2}{*}{$\mathrm{Pa}^{\mathrm{a}}$} & \multicolumn{2}{|c|}{$\begin{array}{l}\text { Dead or } \\
\text { euthanized } \\
\text { dogs }\end{array}$} & \multirow{2}{*}{$\begin{array}{l}\text { OS } \\
\text { (months) }\end{array}$} & \multirow[t]{2}{*}{$\mathbf{P}$} \\
\hline & $\mathbf{N}$ & $\%$ & $\mathbf{N}$ & $\%$ & & & $\mathbf{N}$ & $\%$ & & \\
\hline $\begin{array}{l}\text { Total } \\
\text { number }\end{array}$ & 26 & 100 & 15 & 57.7 & $\begin{array}{l}9.66 \pm \\
0.84\end{array}$ & & 10 & 38.4 & $10.1 \pm 1$ & \\
\hline $\begin{array}{l}\text { Pro-MMP-2 } \\
\text { (ng/lane) }\end{array}$ & & & & & & 0.098 & & & & 0.032 \\
\hline$>1.5$ & 9 & 34.6 & 7 & 77.8 & $\begin{array}{l}15.11 \pm \\
3.79\end{array}$ & & 6 & 66.7 & $\begin{array}{l}24.56 \pm \\
2.73\end{array}$ & \\
\hline$<1.5$ & 17 & 65.4 & 8 & 47 & $\begin{array}{l}23.82 \pm \\
3.19\end{array}$ & & 4 & 23.5 & $\begin{array}{l}31.76 \pm \\
1.88\end{array}$ & \\
\hline $\begin{array}{l}\text { Pro-MMP-9 } \\
\text { (ng/lane) }\end{array}$ & & & & & & 0.240 & & & & 0.008 \\
\hline$>0.9$ & 12 & 46.1 & 8 & 66.7 & $\begin{array}{l}17.75 \pm \\
3.78\end{array}$ & & 8 & 66.7 & $\begin{array}{l}24.32 \pm \\
2.45\end{array}$ & \\
\hline$<0.9$ & 14 & 53.9 & 7 & 50 & $\begin{array}{l}21.92 \pm \\
3.02\end{array}$ & & 2 & 14.3 & $\begin{array}{l}33.5 \pm \\
1.64\end{array}$ & \\
\hline $\begin{array}{l}\text { Active MMP- } \\
\text { 9(ng/lane) }\end{array}$ & & & & & & 0.066 & & & & 0.312 \\
\hline$>1.8$ & 15 & 57.7 & 11 & 73.3 & $\begin{array}{l}15.50 \pm \\
2.76\end{array}$ & & 7 & 46.7 & $\begin{array}{l}26.13 \pm \\
1.94\end{array}$ & \\
\hline$<1.8$ & 11 & 42.3 & 4 & 36.4 & $\begin{array}{l}26.54 \pm \\
3.83\end{array}$ & & 3 & 27.3 & $\begin{array}{l}31.36 \pm \\
2.30\end{array}$ & \\
\hline
\end{tabular}

Kaplan-Meier statistical method; DFS, Disease - free survival time; OS, Overall survival time

Figures 

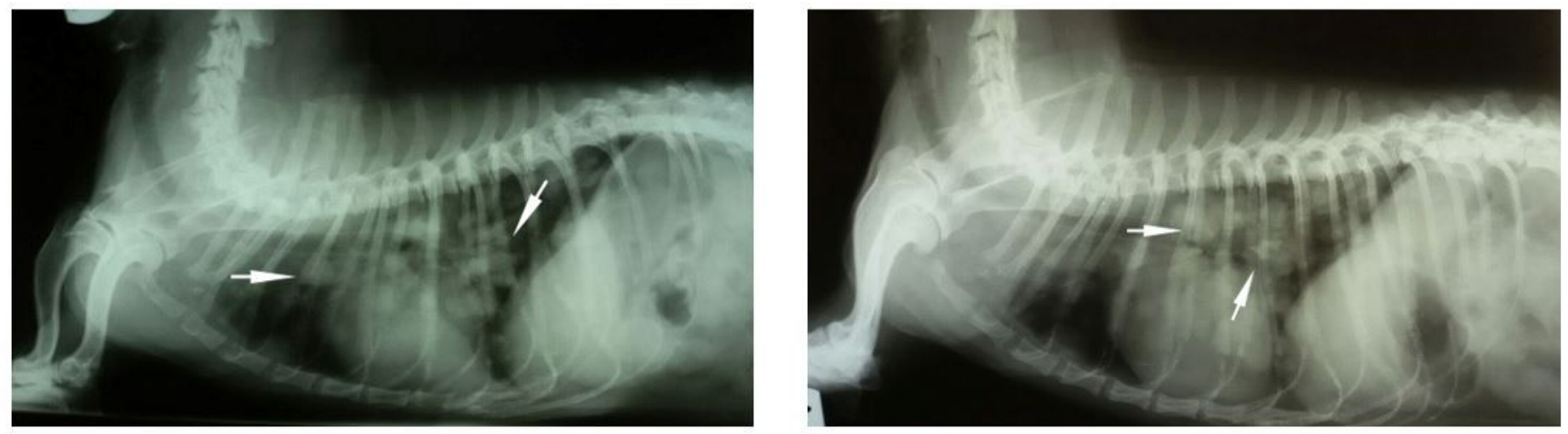

Figure 1

Pulmonary metastasis due to malignant mammary tumor in two dogs. Many cannonballs (arrows) are visible in the lung tissue.
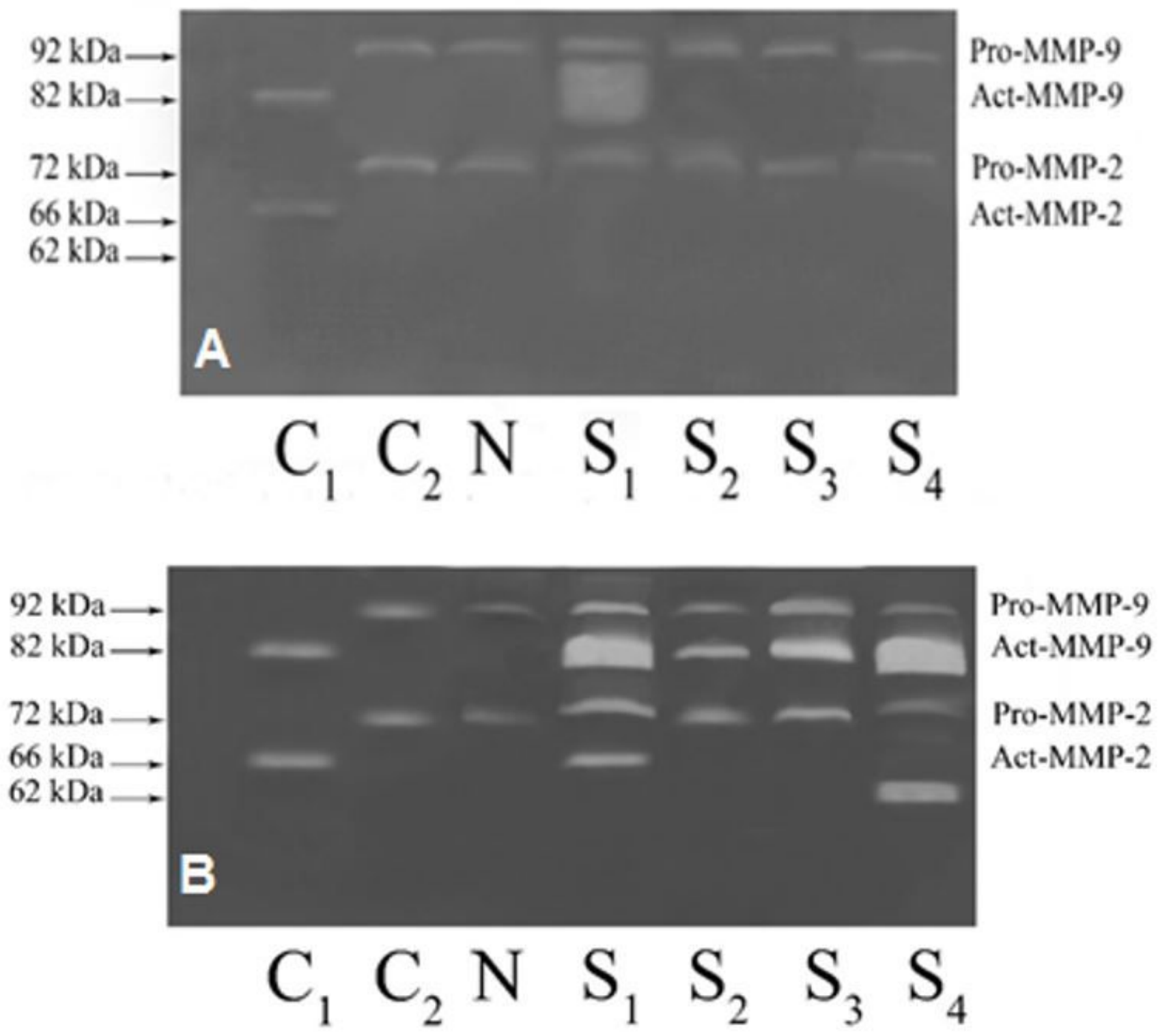
Figure 2

A. Serum gelatin zymography of a dog with benign mixed tumor without metastasis and or recurrence. The active form of MMP-9 was only observed on surgery day (S1). B. Serum gelatin zymography of a dog with inflammatory carcinoma with metastasis and recurrence. Pro-MMP-2 (72-kDa), active MMP-2 (62 kDa and 66 $\mathrm{kDa})$, Pro-MMP-9 $(92 \mathrm{kDa}$ ) and active MMP-9 $(82 \mathrm{kDa})$ bands were observed. Polyacrylamide $10 \%$ containing $0.1 \%$ gel-The $\mathrm{C} 1$ row represents the recombinant human MMP-2 and MMP-9; the C2 row represents a combination of Pro-MMP-2 and Pro-MMP-9; the N row represents control serum. S1 to S4 represent serum samples of preoperative, one month, four months and one year after surgery, respectively.

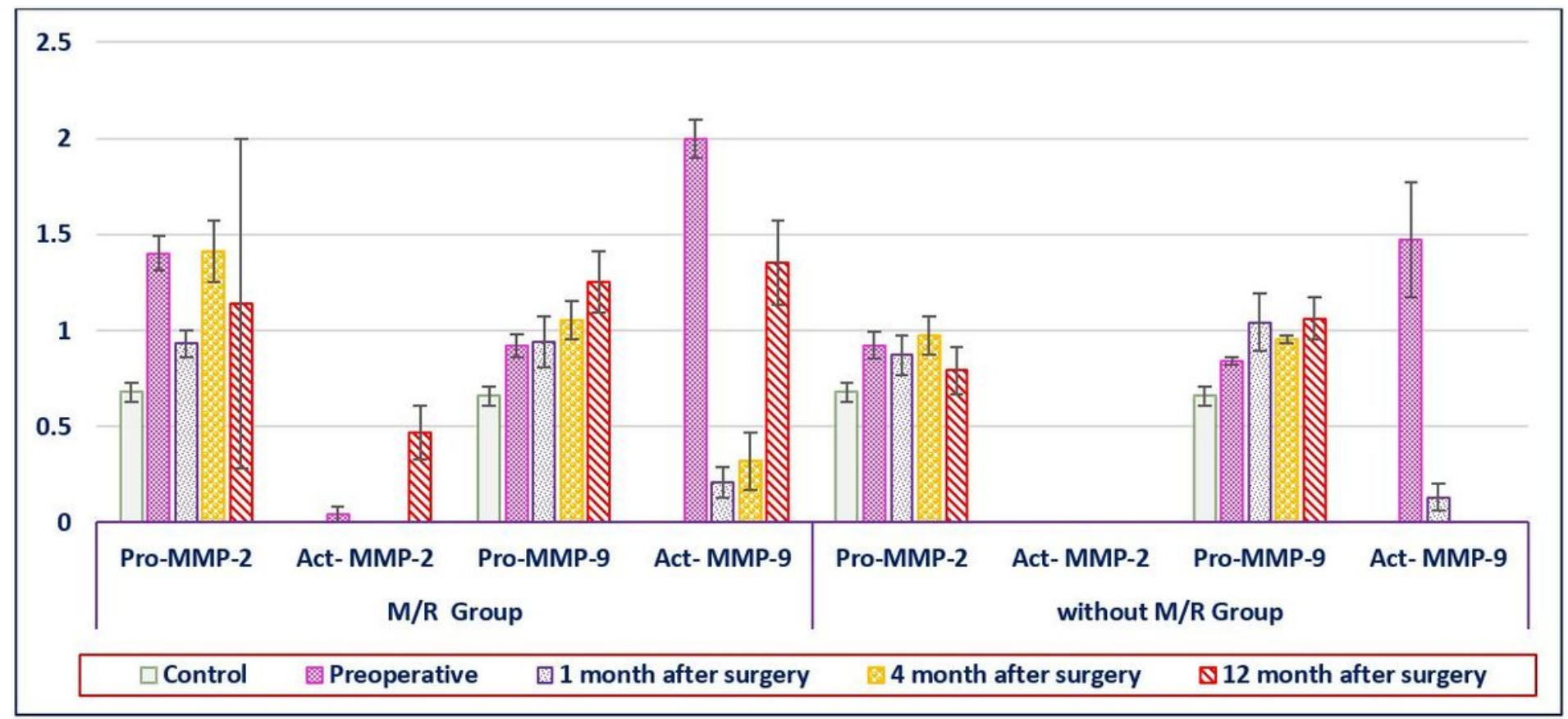

\section{Figure 3}

MMPs (ng/lane) in dogs with and without metastasis and or recurrence $(M / R)$ in different times 